\title{
Istraživanje kemijskog sastava i kvalitete plodova sorti jabuka na M podlogama
}

\author{
Research of chemical composition and quality of fruits \\ of apple varieties on $\mathrm{M}$ rootstocks
}

\section{Miljković}

\section{SAŽETAK}

Istraživanje kemijskog sastava i kvalitete plodova sedam sorti jabuka na šest $\mathrm{M}$ podloga obavljena su tijekom dvije godine u pokusnom voćnjaku na Fakultetskom pokusnom i nastavnom dobru Jazbina kraj Zagreba. Istraživanja su provođena na sortama: Boskoop, Kanada, Jonathan, London pepping, Ljepocvjetka, Mašanka i Zlatna zimska parmenka cijepljenih na podlogama: M 1, M 2, M 4, M 5, M 9 i M 11. Pokusni voćnjak podignut je po metodi randomiziranog bloka u četiri repeticije. U svakoj repeticiji bilo je zastupljeno po pet stabala u kombinaciji sorta podloga, odnosno 20 stabala svake sorte na svakoj podlozi. Stabla s kojih su uzimani uzorci plodova za analizu uzgojena su u obliku popravljene vaze, a bila su dobro razvijena i u punoj rodnosti. Istraživanja su obuhvatila: topivu suhu tvar, ukupne šećere, titracijsku kiselost, jabučnu kiselinu i pH vrijednost. Kvaliteta plodova određena je analizom sklada između količine ukupnih šećera $(\mathrm{g} / \mathrm{l})$ i količine jabučne kiseline $(\mathrm{g} / \mathrm{l})$ po metodi Thiault. Pod utjecajem podloge nisu utvrđene signifikantne razlike u količini ukupnih šećera i kiselina u plodovima istraživanih sorti. Manje razlike u količini ukupnih šećera i kiselina utvrđene su pod utjecajem klimatskih prilika godine, ali ne i pod utjecajem podloge $\mathrm{u}$ istoj godini. Po količini ukupnih šećera istraživane sorte možemo svrstati u tri skupine. Najviše, odnosno podjednako, ukupnih šećera sadrže plodovi Boskopa i Kanade (od 14,5 do 15,0 \%), zatim plodovi Zlatne zimske parmenke (od 13,0 do 13,9), a podjednako plodovi Ljepocvjetke, Jonathana, London peppinga i Mašanke (od 11,5 do 12,5). Između naznačene tri skupine sorata utvrđena je signifikantna razlika na razini LSD P $=5 \%$. Najviše kiseline sadrže plodovi Boskopa i Kanade (od 6,5 do 7,5 g/l), zatim Zlatne zimske parmenke (od 5,5 do 6,0 g/l), podjednako Jonathana i Ljepocvjetke, (4,5 do $5,0 \mathrm{~g} / 1)$, a najmanje, odnosno podjednako Mašanke i London pepping (3,5 do $4,5 \mathrm{~g} / \mathrm{l})$. Između tri skupine sorti utvrđena je signifikantna razlika na razini LSD $\mathrm{P}=5 \%$. Istim redoslijedom razvrstani su plodovi po kvaliteti na osnovi odnosa šećera $(\mathrm{g} / \mathrm{l})$ i jabučne kiseline $(\mathrm{g} / \mathrm{l})$.

Ključne riječi: jabuka, sorta, podloga, kemijski sastav, plod, kvaliteta 


\begin{abstract}
Research on chemical composition and quality of fruit of seven apple varieties on six $\mathrm{M}$ rootstocks were performed during two years in the Faculty experimental orchard Jazbina near Zagreb. Researches have been carried out on varieties: Belle de Boskoop, Reinette de Canada, Jonathan, London pepping, Belle fleur, Mašanka and Reine de reinette on the rootstocks: M 1, M 2, M 4, M 5, M 9 and M 11. The experimental orchard was raised by a randomized block in four repetitions. Each repetition was represented by five trees in a combination of rootstocks and varieties, i.e., 20 trees of each variety on each rootstock. The trees from which analysed fruits samples were taken were cultured in the repaired form of vases, and were well developed in full production period. Researches include: soluble dry matter, total sugars, titration acidity, malic acid and $\mathrm{pH}$ value. The quality of the fruits was determined by analysis of balance between the amount of total sugar $(\mathrm{g} / \mathrm{l})$ and the amount of malic acid $(\mathrm{g} / \mathrm{l})$ by the Thiault index. Under the influence of the rootstocks, no significant difference was found in the amount of total sugars and acids in the fruits of the cultivated varieties. Smaller differences in the amount of total sugars and acids were determined by the climatic conditions of the year but not under the influence of the rootstocks in the same year. The quantity of total sugars of the cultivated variety can be classified into three groups. The most, or equally, the total sugar contains the fruits of Belle de Boskoop, and Reinette de Canada (from 14.5 to $15.0 \%$ ), then the fruits of the Reine de reinette (from 13.0 to 13.9), and equally the fruits of the Belle fleur, Jonathan, London pepping and Mašanka (from 11.5 to 12.5). Between the three groups indicated, a significant difference was found at the LSD $\mathrm{P}=5 \%$ level. Most acids contain Belle de Boskoop and Reinette de Canada fruits (6.5 to $7.5 \mathrm{~g} / \mathrm{l})$, then Reine de reinette $(5.5$ to $6.0 \mathrm{~g} / \mathrm{l})$, equally Jonathan and Belle fleur (4.5 to $5.0 \mathrm{~g} / \mathrm{l})$, and the least, or the same, of Mašanka and London pepping (3.5 to $4.5 \mathrm{~g} / \mathrm{l}$ ). Between the three groups of varieties, a significant difference was observed at the LSD $\mathrm{P}=5 \%$ level. In the same order, fruits are graded for quality based on sugar ratio (g/l) and apple acid $(\mathrm{g} / \mathrm{l})$.
\end{abstract}

Key words: apple, variety, rootstock, chemical composition, fruit, quality

\title{
UVOD I PREGLED LITERATURE
}

Ocjena kvalitete jabuka najčešće se obavlja organoleptički. Takova je ocjena često subjektivna, čak i kada je obavlja više degustatora. Pouzdanije kvalitetu plodova jabuke možemo ocijeniti samo kemijskom analizom. Kemijski sastav i kvaliteta ploda jabuke ovisi o čitavom nizu internih i eksternih faktora. Od internih faktora najveće značenje ima sorta (Miljković 2017., 2018. i drugi). Podloga u prvom redu utječe na bujnost sorte, što se može odraziti na manje ili više promjena u rastu, rodnosti i kvaliteti plodova, kako to izvještavaju brojni istraživači. Ovisno o bujnosti podloge, njen utjecaj se očituje na početak 
rodnosti, količinu priroda, vrijeme trajanja voćnjaka (Comai, 1988., Palara et al. 1998., Sansavini et al., 1999., 2002., Miljković, 1997., 2012. i drugi), rasprostiranje korijenove mreže u tlu i odnos između skeletnog i obrastujućeg korijenja (Miljković 1971., 1982. i drugi) otpornost prema suši i bolestima, a u manjoj i mjeri na početak zrenja i na skladišnu sposobnost, odnosno otpornost ili osjetljivost prema fiziološkim obljenjima ploda u voćnjaku ili skladištu (Ahmet-Amet rt al. 1983., Autio 1994., Tomola et al 1999., Yaha et al. 2004., Berlyng i Poling 1979. i drugi). O utjecaju podloga na rast, rodnost i kvalitetu plodova općenito nalazimo u literaturi puno informacija (Bijelicki et al. 1999., Cobianchi et al. 1986., Engel 1999., Guata et al. 1966., Jadczuk i VolosekStanguet 1999. i drugi), ali kad je riječ konkretno o utjecaju podloge na kemijski sastav plodova tada je malo rezultata egzaktnih istraživanja. Sansavini et al. (1999., 2002.) nisu utvrdili bitne razlike u kemijskom sastavu plodova jabuke Golden Delicious na jedanaest M podloga slabe bujnosti. O utjecaju podloge na mineralni sastav lišća, a posebno primanje kalcija, koji u velikoj mjeri utječe na metaboličke procese u plodu, zdravstveno stanje i pojavu više fiziološka oboljenja plodova, zbog neuravnotežene hranidbe, nalazimo više radova, ali se ne ističe da bitno mijenjaju kemijski sastav plodova sorti $u$ vrijeme berbe.

\section{MATERIJAL I METODE}

Istraživanje kemijskog sastava i kvalitete plodova sorti: Boskop, Kanada, London pepping, Ljepocvjetka, Mašanka i Zlatna zimska parmenka na podlogama: M 1, M 2, M 4, M 5, M 9 i M 11 obavljena su sa stabala u pokusnom voćnjaku Fakultetskog pokusnog i nastavnog dobra Jazbina kraj Zagreba. Pokusni je voćnjak podignut po metodi randomiziranog bloka u četiri repeticije. U svakoj repeticiji bilo je zastupljeno po pet stabala kombinacije sorta podloga, odnosno dvadeset stabala svake sorte na svakoj podlozi. Stabla s kojih su uzimani uzorci plodova za analizu uzgojena su u obliku popravljene vaze, a bila su dobro razvijena i u dobi pune rodnosti. Za analizu su uzimani prosječni uzorci od najmanje jednog kilograma plodova zrelih za potrošnju. Za analizu kemijskog sastava primijenjeni su aktualni klasični postupci u vrijeme obavljenih istraživanja. Plodovi su samljeveni u stroju, a zatim protrljani u tarioniku, da se čestice bolje usitne i dobije što homogenija masa. Od tako pripremljene mase određivana je refraktometrom topiva suha tvar. Očitavanje je vrlo oteščano, ako na prizmu refraktometra dospiju krute čestice. Da se to spriječi, protisnut je sok iz voćne mase kroz tanki sloj vate. Iz istog uzorka 
određeni su ukupni šećeri nakon inverzije prema uputama Cerevitinova, s tom razlikom da je bakreni oksidul odjeljivan filtriranjem kroz stakleni filter lončić Jena G 4 mjesto kroz Allinovu cijev i gravimetrijski određena količina bakrenog oksidula, a ne bakrenog oksida. Količina ukupnih kiselina određena je titracijom s n/10 NaOH uz bromthymolblau. Vrijednost $\mathrm{pH}$ utvrđena je na $\mathrm{pH}$-metru.

\section{REZULTATI}

Rezultati istraživanja važnijih klimatskih prilika za vrijeme istraživanja izneseni su u tablici 1.

Tablica 1. Pregled klimatskih značajki u pokusnom voćnjaku (1958 . - 1959.)

Table 1 Review of climatic characteristics in experimental orchard (1958 - 1959)

\begin{tabular}{|c|c|c|c|c|c|c|c|c|c|c|c|c|c|}
\hline \multirow{2}{*}{$\begin{array}{c}\text { Godina } \\
\text { Year }\end{array}$} & \multicolumn{10}{|c|}{ Mjeseci - Months } & \multirow{2}{*}{$\begin{array}{c}\text { Godišnje } \\
\text { Yearly }\end{array}$} \\
\hline & I & II & III & IV & V & VI & VII & VIII & IX & X & XI & XII & \\
\hline \multicolumn{10}{|c|}{ Srednje mjesečne temperature - Average monthly temperatures $\left({ }^{\circ} \mathrm{C}\right)$} & \\
\hline 1958 & $-0,5$ & 6,0 & 2,6 & 9,1 & 10,8 & 18,8 & 22,5 & 22,4 & 17,8 & 12,4 & 6,2 & 5,1 & 11,9 \\
\hline 1959 & 2,6 & 0,9 & 9,3 & 12,4 & 16,2 & 18,5 & 22,1 & 20,0 & 16,2 & 11,2 & 6,3 & 5,0 & 11,4 \\
\hline \multicolumn{10}{|c|}{ Apsolutne minimalne temperature - Absolute minum temperatures $\left({ }^{\circ} \mathrm{C}\right)$} & \\
\hline 1958 & $-16,4$ & $-11,2$ & $-4,5$ & $-1,8$ & 7,5 & 10,2 & 9,9 & 12,2 & 7,1 & 2,0 & 0,0 & $-8,0$ & $-18,4$ \\
\hline 1959 & $-11,2$ & $-9,3$ & $-0,8$ & 0,0 & 7,6 & 8,2 & 12,6 & 10,0 & 5,8 & 2,8 & 0,2 & $-7,6$ & $-11,8$ \\
\hline \multicolumn{10}{|c|}{ Apsolutne maksimalne temperature - Absolute maximum temperatures $\left({ }^{\circ} \mathrm{C}\right)$} & \\
\hline 1958 & 12,2 & 18,5 & 17,1 & 22,5 & 32,0 & 30,9 & 34,3 & 34,5 & 31,0 & 24,5 & 13,5 & 16,5 & 34,5 \\
\hline 1959 & 12,6 & 15,5 & 21,5 & 22,2 & 27,2 & 28,4 & 31,8 & 29,2 & 20,2 & 20,2 & 13,4 & 15,8 & 31,8 \\
\hline & \multicolumn{10}{|c|}{ Mjesečne oborine u mm - Precipitation in mm } \\
\hline 1958 & 65 & 62 & 56 & 57 & 39 & 132 & 48 & 41 & 33 & 77 & 104 & 84 & 794 \\
\hline 1959 & 99 & 7 & 32 & 75 & 105 & 243 & 134 & 169 & 59 & 32 & 50 & 215 & 1222 \\
\hline
\end{tabular}

Istraživanja su provedena tijekom dvije godine od kojih je jedna (1958.) bila sušna, a druga (1959.) vlažna. Srednje mjesečne temperature bile su u vrijeme zrenja plodova podjednake u obje godine. Apsolutne maksimalne temperature za vrijeme zrenja plodova nisu se bitno razlikovale.

Rezultati istraživanja topive suhe tvari izneseni su u tablici 2. 
I. Miljković: Istraživanje kemijskog sastava i kvalitete plodova sorti jabuka na M podlogama

Tablica 2. Topiva suha tvar

Table 2 Soluble dry matter

\begin{tabular}{|c|c|c|c|c|c|c|c|c|}
\hline \multirow{2}{*}{ Sorta - Variety } & \multirow{2}{*}{$\begin{array}{c}\text { Godina } \\
\text { Year }\end{array}$} & \multicolumn{6}{|c|}{ Podloga - Rootstock } & \multirow{2}{*}{$\bar{x}$} \\
\hline & & M 1 & M 2 & M 4 & M 5 & M 9 & M 11 & \\
\hline \multirow{3}{*}{$\begin{array}{c}\text { Boskop - } \\
\text { Belle de Boskoop }\end{array}$} & 1958 & 17,2 & 17,7 & 17,2 & 18,4 & 17,6 & 17,3 & 17,6 \\
\hline & 1959 & 17,3 & 17,3 & 18,1 & 17,0 & 15,6 & 17,8 & 17,2 \\
\hline & $\bar{x}$ & 17,3 & 17,5 & 17,7 & 17,7 & 16,6 & 17,6 & 17,4 \\
\hline \multirow{3}{*}{$\begin{array}{c}\text { Kanada - } \\
\text { Reinette de Canada }\end{array}$} & 1958 & 17,8 & 18,8 & 17,3 & 20,7 & 17,9 & 16,9 & 18,2 \\
\hline & 1959 & 17,7 & 16,6 & 16,7 & 17,1 & 16,7 & 16,1 & 16,8 \\
\hline & $\bar{x}$ & 17,8 & 17,7 & 17,0 & 18,9 & 17,3 & 16,5 & 17,5 \\
\hline \multirow{3}{*}{$\begin{array}{c}\text { Zlatna zimska } \\
\text { parmenka } \\
\text { Reine de reinette }\end{array}$} & 1958 & 15,4 & 16,9 & 15,9 & 14,8 & 16,7 & 15,1 & 15,8 \\
\hline & 1959 & 18,6 & 18,0 & 18,2 & 17,0 & 17,7 & 14,8 & 17,4 \\
\hline & $\bar{x}$ & 17,0 & 17,5 & 17,1 & 15,9 & 17,2 & 15,0 & 16,6 \\
\hline \multirow{3}{*}{ Jonathan } & 1958 & 14,0 & 14,9 & 13,8 & 14,0 & 13,8 & 13,6 & 14,0 \\
\hline & 1959 & 14,4 & 16,0 & 15,8 & 16,4 & 15,4 & 15,2 & 15,5 \\
\hline & $\bar{x}$ & 14,2 & 15,5 & 14,8 & 15,2 & 14,6 & 14,4 & 14,8 \\
\hline \multirow{3}{*}{ London pepping } & 1958 & 15,7 & 12,7 & 12,4 & 12,6 & 12,8 & 12,6 & 13,1 \\
\hline & 1959 & 16,4 & 16,0 & 16,1 & 14,6 & 15,7 & 15,7 & 15,8 \\
\hline & $\bar{x}$ & 16,1 & 14,4 & 14,3 & 13,7 & 14,3 & 14,2 & 14,5 \\
\hline \multirow{3}{*}{$\begin{array}{l}\text { Ljepocvjetka } \\
\text { Belle fleur }\end{array}$} & 1958 & 15,6 & 15,6 & 15,0 & 15,6 & 14,9 & 15,6 & 15,4 \\
\hline & 1958 & 16,6 & 16,6 & 16,4 & 16,8 & 15,0 & 16,4 & 16,3 \\
\hline & $\bar{x}$ & 16,1 & 16,1 & 15,7 & 16,2 & 15,0 & 16,0 & 15,9 \\
\hline \multirow{3}{*}{$\begin{array}{l}\text { Mašanka } \\
\text { Mašancke }\end{array}$} & 1958 & 15,4 & 15,5 & 16,0 & 15,1 & 15,3 & 15,0 & 15,4 \\
\hline & 1959 & 15,2 & 14,7 & 17,0 & 15,7 & 15,6 & 15,0 & 15,5 \\
\hline & $\bar{x}$ & 15,3 & 15,1 & 16,5 & 15,4 & 15,5 & 15,0 & 15,5 \\
\hline
\end{tabular}

$\mathrm{Na}$ tablici vidimo da postoje razlike $\mathrm{u}$ količini topive suhe tvari između sorti na svim istraživanim podlogama.

$\mathrm{Na}$ tablici 3. izneseni su rezultati istraživanja količine ukupnih šećera. 
I. Miljković: Istraživanje kemijskog sastava i kvalitete plodova sorti jabuka na M podlogama

Tablica 3. Ukupni šećeri u \% suhe tvari

Table 3 Total sugars in \% of dry matter

\begin{tabular}{|c|c|c|c|c|c|c|c|c|}
\hline \multirow{2}{*}{ Sorta - Variety } & \multirow{2}{*}{$\begin{array}{l}\text { Godina } \\
\text { Year }\end{array}$} & \multicolumn{6}{|c|}{ Podloga - Rootstock } & \multirow{2}{*}{$\begin{array}{l}\text { sig. dif. } \\
\mathrm{P}=05 \%\end{array}$} \\
\hline & & M 1 & M 2 & M 4 & M 5 & M 9 & M 11 & \\
\hline \multirow{3}{*}{$\begin{array}{c}\text { Boskop - } \\
\text { Belle de Boskoop }\end{array}$} & 1958 & 14,41 & 14,29 & 13,92 & 14,24 & 14,26 & 14,27 & n. s. \\
\hline & 1959 & 14,30 & 14,20 & 13,90 & 14,05 & 14,31 & 14,28 & n. s. \\
\hline & $\bar{x}$ & 14,36 & 14,25 & 13,91 & 14,15 & 14,29 & 14,28 & \\
\hline \multirow{3}{*}{$\begin{array}{l}\text { Kanada - } \\
\text { Reinette de } \\
\text { Canada }\end{array}$} & 1958 & 14,22 & 14,68 & 14,75 & 14,70 & 14,57 & 13,86 & n. s. \\
\hline & 1959 & 14,12 & 13,74 & 13,79 & 13,66 & 13,69 & 13,98 & n. s. \\
\hline & $\bar{x}$ & 14,17 & 14,21 & 14,27 & 14,18 & 14,13 & 13,92 & \\
\hline \multirow{3}{*}{$\begin{array}{c}\text { Zlatna zimska } \\
\text { parmenka } \\
\text { Reine de reinette }\end{array}$} & 1958 & 12,61 & 12,76 & 13,01 & 12,25 & 12,88 & 12,83 & n. s. \\
\hline & 1959 & 14,82 & 14,65 & 14,88 & 14,75 & 15,00 & 14,85 & n. s. \\
\hline & $\bar{x}$ & 13,72 & 13,71 & 13,95 & 13,50 & 13,94 & 13,84 & \\
\hline \multirow{3}{*}{ Jonathan } & 1958 & 12,94 & 12,83 & 12,91 & 12,75 & 12,98 & 12,63 & n. s. \\
\hline & 1959 & 14,50 & 14,15 & 13,94 & 14,02 & 14,08 & 13,95 & n. s. \\
\hline & $\bar{x}$ & 13,72 & 13,49 & 13,43 & 13,39 & 13,53 & 13,29 & \\
\hline \multirow{3}{*}{ London pepping } & 1958 & 10,22 & 10,39 & 10,00 & 10,08 & 10,60 & 10,16 & n. s. \\
\hline & 1959 & 13,42 & 13,64 & 13,72 & 13,50 & 13,45 & 13,42 & n. s. \\
\hline & $\bar{x}$ & 11,82 & 12,02 & 11,86 & 11,79 & 12,03 & 11,79 & \\
\hline \multirow{3}{*}{$\begin{array}{l}\text { Ljepocvjetka } \\
\text { Belle fleur }\end{array}$} & 1958 & 12,46 & 12,41 & 11,74 & 12,43 & 11,76 & 11,78 & n. s. \\
\hline & 1958 & 13,98 & 13,94 & 13,57 & 14,08 & 13,75 & 13,58 & n.s.. \\
\hline & $\bar{x}$ & 13,22 & 13,18 & 12,66 & 13,26 & 12,76 & 12,68 & \\
\hline \multirow{3}{*}{$\begin{array}{l}\text { Mašanka } \\
\text { Mašancke }\end{array}$} & 1958 & 11,71 & 11,45 & 11,31 & 11,52 & 11,35 & 11,35 & n. s. \\
\hline & 1959 & 12,16 & 11,98 & 12,33 & 12,73 & 12,68 & 12,06 & n. s. \\
\hline & $\bar{x}$ & 11,94 & 11,72 & 11,82 & 12,13 & 12,02 & 11,71 & \\
\hline
\end{tabular}

Na tablici vidimo da pod utjecajem podloge niti u 1958. niti u 1959. nisu utvrđene statistički opravdane razlike u količini ukupnih šećera. Plodovi sorte Boskop sadržavali su u obje godine na istraživanim podlogama podjednaku količinu šećera. Plodovi sorte Kanada sadržavali su u sušnoj godini manje ukupnih šećera na podlogama M 2 i M 4, a više na podlogama M 5 i M 9. Plodovi sorti: Jonathan, Ljepocvjetka, London pepping Mašanka i Zlatna zimska parmenka sadržavali su u vlažnijoj 1959. godini više ukupnih šećera nego u sušnijoj 1958. godini. Međutim, u obje godine nisu se odrazile razlike unutar pojedine sorte pod utjecajem podloge.

$\mathrm{Na}$ tablici 4 izneseni su rezultati istraživanja ukupne kiseline (titracijska kiselost). 
I. Miljković: Istraživanje kemijskog sastava i kvalitete plodova sorti jabuka na M podlogama

Tablica 4. Ukupne kiseline (titracijska kiselost) u g/l

Table 4 Total acids (titration acidity) in $\mathrm{g} / \mathrm{l}$

\begin{tabular}{|c|c|c|c|c|c|c|c|c|}
\hline \multirow{2}{*}{ Sorta - variety } & \multirow{2}{*}{$\begin{array}{l}\text { Godina } \\
\text { Year }\end{array}$} & \multicolumn{6}{|c|}{ Podloga - Rootstock } & \multirow{2}{*}{$\begin{array}{l}\text { sign. dif. } \\
\mathrm{P}=0,5 \%\end{array}$} \\
\hline & & M 1 & M 2 & M 4 & M 5 & M 9 & M 11 & \\
\hline \multirow{3}{*}{$\begin{array}{c}\text { Boskop - } \\
\text { Belle de Boskoop }\end{array}$} & 1958 & 7,7 & 7,8 & 7,7 & 8,0 & 8,0 & 7,7 & n. s. \\
\hline & 1959 & 7,8 & 7,9 & 8,0 & 7,9 & 7,7 & 7,8 & n. s. \\
\hline & $\bar{x}$ & 7,75 & 7,85 & 7,85 & 7,95 & 7,85 & 7,75 & \\
\hline \multirow{3}{*}{$\begin{array}{c}\text { Kanada - } \\
\text { Reinette de Canada }\end{array}$} & 1958 & 6,4 & 6,1 & 6,6 & 6,3 & 6,3 & 6,0 & n. s. \\
\hline & 1959 & 6,5 & 6,5 & 6,7 & 6,9 & 6,9 & 6,7 & n. s. \\
\hline & $\bar{x}$ & 6,45 & 6,30 & 6,65 & 6,60 & 6,60 & 6,35 & \\
\hline \multirow{3}{*}{$\begin{array}{c}\text { Zlatna zimska } \\
\text { parmenka } \\
\text { Reine de reinette }\end{array}$} & 1958 & 4,8 & 4,6 & 5,0 & 5,0 & 5,0 & 4,6 & n. s. \\
\hline & 1959 & 5,4 & 4,6 & 4,9 & 5,2 & 5,1 & 5,0 & n. s. \\
\hline & $\bar{x}$ & 5,10 & 4,60 & 4,95 & 5,10 & 5,05 & 4,80 & \\
\hline \multirow{3}{*}{ Jonathan } & 1958 & 5,1 & 4,8 & 4,9 & 4,9 & 4,8 & 4,8 & n. s. \\
\hline & 1959 & 6,7 & 6,7 & 6,5 & 6,6 & 5,9 & 6,2 & n. s. \\
\hline & $\bar{x}$ & 5,90 & 5,75 & 5,70 & 5,75 & 5,35 & 5,50 & \\
\hline \multirow{3}{*}{ London pepping } & 1958 & 2,7 & 3,1 & 2,7 & 2,7 & 2,8 & 2,9 & n. s. \\
\hline & 1959 & 4,5 & 3,4 & 4,5 & 4,4 & 4,3 & 4,4 & n. s. \\
\hline & $\bar{x}$ & 3,60 & 3,25 & 3,60 & 3,55 & 3,55 & 3,65 & \\
\hline \multirow{3}{*}{$\begin{array}{l}\text { Ljepocvjetka } \\
\text { Belle fleur }\end{array}$} & 1958 & 5,0 & 4,6 & 5,1 & 5,0 & 5,1 & 4,6 & n. s. \\
\hline & 1959 & 4,0 & 4,5 & 3,4 & 4,0 & 3,2 & 4,5 & n. s. \\
\hline & $\bar{x}$ & 4,50 & 4,55 & 4,25 & 4,50 & 4,15 & 4,55 & \\
\hline \multirow{3}{*}{$\begin{array}{l}\text { Mašanka } \\
\text { Mašancke }\end{array}$} & 1958 & 3,1 & 3,2 & 3,3 & 3,1 & 3,2 & 3,1 & n. s. \\
\hline & 1959 & 4,7 & 4,2 & 4,9 & 4,4 & 4,5 & 4,6 & n. s. \\
\hline & $\bar{x}$ & 3,90 & 3,70 & 4,10 & 3,75 & 3,85 & 3,85 & \\
\hline
\end{tabular}

Na tablici vidimo da su plodovi sorti: Boskopa, Kanade i Zlatne zimske parmenke sadržavali podjednaku količinu kiseline u obje godine. Nasuprot tome plodovi sorti: Jonathana, London peppinga i Mašanke sadržavali su u vlažnijoj 1959. godini na svim podlogama veću količinu kiseline. Jedino su plodovi sorte Ljepocvjetka sadržavali više kiseline u sušnijoj 1958. godini nego u vlažnijoj 1959. godini.

Na tablici 5 izneseni su rezultati istraživanja pH vrijednosti. 
I. Miljković: Istraživanje kemijskog sastava i kvalitete plodova sorti jabuka na M podlogama

\section{Tablica 5. pH vrijednost}

Table $5 \mathrm{pH}$ value

\begin{tabular}{|c|c|c|c|c|c|c|c|c|}
\hline \multirow{2}{*}{ Sorta - variety } & \multirow{2}{*}{$\begin{array}{l}\text { Godina } \\
\text { Year }\end{array}$} & \multicolumn{6}{|c|}{ Podloga - Rootstock } & \multirow{2}{*}{$\bar{x}$} \\
\hline & & M 1 & M 2 & M 4 & M 5 & M 9 & M 11 & \\
\hline \multirow{3}{*}{$\begin{array}{c}\text { Boskop - } \\
\text { Belle de Boskoop }\end{array}$} & 1958 & 3,50 & 3,33 & 3,35 & 3,33 & 3,31 & 3,35 & 3,36 \\
\hline & 1959 & 3,35 & 3,29 & 3,24 & 3,57 & 3,32 & 3,20 & 3,33 \\
\hline & $\bar{x}$ & 3,43 & 3,31 & 3,30 & 3,45 & 3,32 & 3,28 & 3,35 \\
\hline \multirow{3}{*}{$\begin{array}{l}\text { Kanada - } \\
\text { Reinette de } \\
\text { Canada }\end{array}$} & 1958 & 3,45 & 3,50 & 3,45 & 3,31 & 3,46 & 3,46 & 3,44 \\
\hline & 1959 & 3,42 & 3,42 & 3,50 & 3,35 & 3,33 & 3,40 & 3,40 \\
\hline & $\bar{x}$ & 3,44 & 3,46 & 3,48 & 3,33 & 3,40 & 3,43 & 3,42 \\
\hline \multirow{3}{*}{$\begin{array}{c}\text { Zlatna zimska } \\
\text { parmenka } \\
\text { Reine de reinette }\end{array}$} & 1958 & 3,45 & 3,45 & 3,44 & 3,44 & 3,44 & 3,47 & 3,45 \\
\hline & 1959 & 3,43 & 3,46 & 3,31 & 3,45 & 3,46 & 3,43 & 3,42 \\
\hline & $\bar{x}$ & 3,44 & 3,46 & 3,38 & 3,45 & 3,45 & 3,45 & 3,44 \\
\hline \multirow{3}{*}{ Jonathan } & 1958 & 3,41 & 3,42 & 3,44 & 3,44 & 3,51 & 3,44 & 3,44 \\
\hline & 1959 & 3,42 & 3,43 & 3,44 & 3,44 & 3,51 & 3,50 & 3,46 \\
\hline & $\bar{x}$ & 3,42 & 3,43 & 3,44 & 3,44 & 3,51 & 3,47 & 3,45 \\
\hline \multirow{3}{*}{ London pepping } & 1958 & 3,93 & 3,88 & 3,94 & 3,93 & 3,93 & 3,90 & 3,92 \\
\hline & 1959 & 3,56 & 3,58 & 3,58 & 3,60 & 3,65 & 3,60 & 3,60 \\
\hline & $\bar{x}$ & 3,75 & 3,73 & 3,76 & 3,77 & 3,79 & 3,75 & 3,76 \\
\hline \multirow{3}{*}{$\begin{array}{l}\text { Ljepocvjetka } \\
\text { Belle fleur }\end{array}$} & 1958 & 3,52 & 3,57 & 3,53 & 3,53 & 3,40 & 3,55 & 3,52 \\
\hline & 1958 & 3,49 & 3,54 & 3,59 & 3,59 & 3,48 & 3,42 & 3,52 \\
\hline & $\bar{x}$ & 3,51 & 3,56 & 3,56 & 3,56 & 3,44 & 3,49 & 3,52 \\
\hline \multirow{3}{*}{$\begin{array}{l}\text { Mašanka } \\
\text { Mašancke }\end{array}$} & 1958 & 3,85 & 3,79 & 3,79 & 3,84 & 3,82 & 3,82 & 3,82 \\
\hline & 1959 & 3,65 & 3,32 & 3,65 & 3,77 & 3,65 & 3,65 & 3,62 \\
\hline & $\bar{x}$ & 3,75 & 3,52 & 3,72 & 3,81 & 3,74 & 3,74 & 3,72 \\
\hline
\end{tabular}

$\mathrm{Na}$ tablici vidimo da su plodovi sorti na istraživanim podlogama imali podjednaku $\mathrm{pH}$ vrijednost. Manje razlike postoje između sorata.

$\mathrm{Na}$ tablici 6 izneseni su podatci o kvaliteti plodova prema Thiault-ovu indeksu.

Thiault indeks izračuna se po obrascu: Ukupni šećeri g/l + ukupne kiseline x 10 (TS g/1 + AC g/l x 10). Napomena: Ukupni šećer pretvaramo u grame na litru tako da množimo sa 10,6, a od produkta odbijemo 20,6, a ukupne kiseline pretvaramo u jabučnu kiselinu po obrascu titracijska kiselost x 0,67 x $10 \mathrm{~g} / 1$ šećera $+\mathrm{g} / 1$ jabučne kiseline. 
I. Miljković: Istraživanje kemijskog sastava i kvalitete plodova sorti jabuka na M podlogama

Tablica 6. Kvaliteta plodova sorti na „M“ podlogama po Thiault-ovom indeksu

Table 6 Quality of fruits of varieties on "M" rootstocks according to the Thiault index

\begin{tabular}{|c|c|c|c|c|c|c|c|c|}
\hline \multirow{2}{*}{ Sorta - variety } & \multirow{2}{*}{$\begin{array}{l}\text { Godina } \\
\text { Year }\end{array}$} & \multicolumn{6}{|c|}{ Podloga - Rootstock } & \multirow{2}{*}{$\bar{x}$} \\
\hline & & M 1 & M 2 & M 4 & M 5 & M9 & M 11 & \\
\hline \multirow{3}{*}{$\begin{array}{c}\text { Boskop - Belle de } \\
\text { Boskoop }\end{array}$} & 1958 & 183,6 & 163,7 & 178,5 & 186,5 & 189,4 & 182,1 & 180,6 \\
\hline & 1959 & 183,1 & 177,3 & 179,3 & 180,6 & 178,6 & 182,9 & 180,3 \\
\hline & $\bar{x}$ & 183,4 & 170,5 & 178,9 & 183,6 & 184,0 & 182,5 & 180,5 \\
\hline \multirow{3}{*}{$\begin{array}{c}\text { Kanada - Reinette de } \\
\text { Canada }\end{array}$} & 1958 & 179,6 & 167,5 & 183,8 & 184,1 & 166,2 & 171,6 & 175,5 \\
\hline & 1959 & 174,6 & 172,2 & 166,0 & 168,9 & 175,0 & 173,1 & 171,6 \\
\hline & $\bar{x}$ & 177,1 & 169,9 & 174,9 & 176,5 & 170,6 & 172,4 & 173,6 \\
\hline \multirow{3}{*}{$\begin{array}{l}\text { Zlatna zimska parmenka } \\
\text { Reine de reinette }\end{array}$} & 1958 & 145,1 & 145,4 & 151,9 & 142,8 & 150,0 & 146,1 & 146,9 \\
\hline & 1959 & 181,2 & 172,4 & 169,0 & 179,9 & 178,0 & 174,3 & 175,8 \\
\hline & $\bar{x}$ & 163,2 & 158,9 & 160,5 & 161,4 & 164,0 & 160,2 & 161,4 \\
\hline \multirow{3}{*}{ Jonathan } & 1958 & 121,8 & 122,3 & 149,0 & 148,0 & 150,0 & 145,3 & 139,4 \\
\hline & 1959 & 166,4 & 168,7 & 160,2 & 171,2 & 168,8 & 168,9 & 167,4 \\
\hline & $\bar{x}$ & 144,1 & 145,5 & 154,6 & 159,6 & 159,4 & 157,1 & 153,4 \\
\hline \multirow{3}{*}{ London pepping } & 1958 & 137,3 & 110,1 & 98,9 & 112,6 & 109,7 & 117,1 & 114,3 \\
\hline & 1959 & 151,7 & 153,3 & 154,3 & 152,8 & 150,7 & 151,1 & 152,3 \\
\hline & $\bar{x}$ & 144,5 & 131,7 & 126,6 & 132,7 & 130,2 & 134,1 & 133,3 \\
\hline \multirow{3}{*}{$\begin{array}{l}\text { Ljepocvjetka } \\
\text { Belle fleur }\end{array}$} & 1958 & 148,3 & 156,4 & 138,0 & 143,3 & 132,8 & 135,4 & 142,4 \\
\hline & 1959 & 154,4 & 151,2 & 145,9 & 154,4 & 147,3 & 153,1 & 151,1 \\
\hline & $\bar{x}$ & 151,4 & 153,8 & 142,0 & 148,9 & 140,1 & 144,3 & 146,8 \\
\hline \multirow{3}{*}{$\begin{array}{l}\text { Mašanka } \\
\text { Mašancke }\end{array}$} & 1958 & 124,3 & 122,2 & 123,3 & 119,7 & 121,1 & 120,4 & 121,8 \\
\hline & 1959 & 139,6 & 127,7 & 133,5 & 135,7 & 144,4 & 132,9 & 135,6 \\
\hline & $\bar{x}$ & 132,0 & 125,0 & 128,4 & 127,7 & 132,8 & 126,7 & 128,8 \\
\hline
\end{tabular}

$\mathrm{Na}$ tablici vidimo da su najbolju kvalitetu postigli plodovi sorti: Boskop, Kanada i Zlatna zimska parmenka, podjednaku sorte: Jonathan, London pepping i Ljepocvjetka, a osjetno lošiju plodovi sorte Mašanka. U sušnijoj 1958. godini lošiju kvalitetu plodova na svim podlogama imale su sorte: Zlatna zimska parmenka, Jonathan, London pepping i Mašanka. Plodovi sorte Ljepocvjetke imali sa također lošiju kvalitetu u 1958. godini nego u vlažnijoj 1959. osim na podlozi M 4 kada je kvaliteta bila podjednaka u obje godine. Podjednaku 
kvalitetu imali su uglavnom plodovi sorte Boskop i Kanada u obje godine na svim podlogama. Nešto malo lošiju kvaliteta u sušnijoj 1958. godini imali su plodovi Boskopa ma M 2, a Kanade na M 2 i M 4 nego u vlažnijoj 1959. godini.

\section{ZAKLJUČAK}

$\mathrm{Na}$ temelju provedenih istraživanja kemijskog sastava i kvalitete ploda sorti: Boskop, Jonathan, Kanada, Ljepocvjetka, London pepping, Mašanka i Zlatna zimska parmenka na podlogama: M 1, M 2, M 4, M 5, M 9 i M 11, obavljenih u pokusnom voćnjaku na području Sjeverozapadne Hrvatske mogu se izvesti slijedeći zaključci.

- Sve su sorte na istraživanim podlogama postigle vrlo dobru kvalitetu.

- Pod utjecajem podloge nisu utvrđene signifikantne razlike u količini ukupnih šećera i kiseline u plodovima istraživanih sorti.

- Manje razlike u količini ukupnih šećera i kiseline utvrđene su pod utjecajem klimatskih prilika godine, ali ne i pod utjecajem podloge u istoj godini.

- Po količini ukupnih šećera istraživane sorte možemo svrstati tri skupine. U prvoj su skupini sorte Boskop i Kanada, čiji plodovi sadrže najviše, odnosno od 14,5 do 15,0 \% ukupnih šećera. U drugu skupnu svrstana je sorta Zlatna zimska parmenka, koje plodovi sadrže od 13,0 do 13,9\% ukupnih šećera. U trećoj su skupni sorte: Jonathan, Ljepocvjetka, London pepping i Mašanka, kojima plodovi sadrže podjednako, odnosno od 11,5 do $125 \%$ ukupnih šećera. Između naznačene tri skupine sorata utvrđena je signifikantna razlika na razini LSD $\mathrm{P}=5 \%$.

- Najviše kiseline sadrže plodovi Boskopa i Kanade (6,5 do 7,5 g/l), zatim Zlatne zimske parmenke (od 5,5 do $6,0 \mathrm{~g} / \mathrm{l}$ ), podjednako Jonathana i Ljepocvjetke (od 4,5 do 5,0 g/l)

- Istim redoslijedom razvrstani su plodovi istraživanih sorti po kvaliteti na osnovi odnosa ukupnih šećera $(\mathrm{g} / \mathrm{l}) \mathrm{i}$ jabučne kiseline $(\mathrm{g} / \mathrm{l})$.

\section{LITERATURA}

AHMET-AMEN et al. (1983.): Fruit quality and storage ability of two apple cultivars as affected by rootstock, planting systems, irrigation and growth retardant

AUTIO W. R., (1994.): Rootstock affects apple ripening, quality and storability. Compact Fruit Tree 27: pp. 41 - 47. 
AUTIO W. R. A., HAYDEN R. A., MICKE W. C., BROWN G. R., (1996.): Rootstock affects ripening, color, and shape of Starkspur Supreme Delicious apples. Fruit Var. 1. 50: pp. 45-53.

BEN J. M., (1999.): Apple rootstock on mineral elements concentration in Gloster apple, Apple rootstocks for intensive orchard pp. 13-15, Warszawa

BIELICKI P., CZYNCZYK A., BARTOSIEWICZ B., (1999.): Effects of new polish rootstocks and some M 9 clones on growth, cropping and fruit quality of three apple cultivars, Apple rootstocks for intensive orchard, pp. 17-18. Warszawa.

CALLESON O., (1997.): Testing 20 apple rootstocks, Acta Horticulturae 451: pp. 137-146

CEREVITINOV P., (1933.): Himija svežih plodov i ovošćej, Moskva

COBIANCHI D; FAEDI W; BIGUZZI M., (1986.): Influenza di 4 portinnesti clonali sul comportamento vegeto-produttivo di 6 cultivar di melo. La coltura di melo verso anni 90: pp. 409-414, Cordenos.

COMAI M., (1988.): Comportamento vegetativo e produttivo di Golden Delicious su portinnesti clonali deboli. Portinnesti delle piante da frutto, pp. 291-204

ENGEL A., (1999.): Effect of different M 9 subclones and M 9-cross breed rootstocks on growth, yield and fruit quality of three apple cultivars, Apple rootstocks for intensive orchards, pp. 25-26. Warszawa.

FALLAHI E., RICHARDSON D. G. WESTWOOD M. N., (1985.): Quality of apple fruit a high density orchards as influenced by rootstock fertilizers maturity and storage. J. Amer. Soc. Hort. Sci. 110 (1). pp. 149-153.

GUATA R., GOTO K., KONISAWA T., HARADA R., (1966.): Production and fruit quality of four apple cultivars on three different rootstocks and et different planting densities. Acta Hort. 160: pp. 97-103.

HULME A. C., (1971.): Pome fruits, in Biochemistry of Fruits and Their Products. Academic Press London.

JADREZAK E., KOBYLIVSAKA J., ŽELAZO N., (1997.): Effect of rootstocks upon leaf mineral composition of non bearing Jonagold Apple trees. Acta Hort. 383: pp. 345-352. 
IVANOVA A., Mineralnij sostav i ležkost plodov jablonji na karlikovih podvoojah. Sadovodstvo i vinogradarstvo, npo. 2 pp. 8-9

JADCZUK E., C. R. VOLOSEK-STANGUET., (1999.): Cropping and fruit quality of Jonagold apple trees depending on rootstocks. Apple rootstocks for intensive orchard, pp. 45-47.

KIKLYS D., USERLIS N., KVIKLIENE N., (1999.): Rootstock effect on "Jonagold" apple tree growth, yield and fruit quality. Apple rootstocks for intensive orchards, pp. 67-68. Warszawa.

KRUCZYNSKA D., CZYNCZYK A., BUCZEK M., (1999.): Effect of rootstock, weather and soil conditions upon growth, cropping and fruit quality of "Galla Musat" apple trees. Apple rootstocks for intensive orchards, pp. 61-62. Warszawa.

ŠTAMPAR KATARINA, (1952.): Odnos šećera i refraktometrijeske vrijednosti kod voća, Poljoprivredna znanstvena smotra br. 13: pp. 155-168.

MILJKOVIĆ I., (1971.): Korijenova mreža stabala Jonathana na vegetativnim i generativnim podlogama u aluvijalnom tlu, Agronomski glasnik 1-2: pp. 41-52.

MILJKOVIĆ I., (1982.): Ricerche sugli apparati radicali del melo innestati su diversi portinnesti in pseudogley sui pendii della montagna di Zagabria. 2. Convegno internazionale di frutticoltura montana, Saint Vincent.

MILJKOVIĆ I., (1997.): Podloge za jabuku, Pomologia Croatica, Vol. 3 No. 1-4: pp. 47-57

MILJKOVIĆ I., (2012.): Podloge za jabuku. Poljoprivredni institut Osijek, pp 1-65, Osijek.

MILJKOVIĆ I., (2017.): Kemijski sastav plodova 40 sorti jabuke uzgajanih u gornjem Međimurju, Zbornik sažetaka, 10. Međunarodni kongres Oplemenjivanje bilja, sjemenarstvo i rasadničarstvo, Sv. Martin na Muri

MILJKOVIĆ I., (2018.): Istraživanje utjecaja klimatskih prilika na kemijski sastav i kvalitetu plodova sorti jabuka u Hrvatskoj, Zbornik sažetaka 11. Međunarodni kongres Oplemenjivanje bilja, sjemenarstvo i rasadničarstvo, Umag. 
PLARA U., COLOMBO R., CARUSO S., CAVICCHI I., (1998.): Confronto tra i cloni di M 9 per l'innesto del melo. Portinnesti dei fruttiferi, Notiziario tecnico N. 56.

SANSAVINI S., MUSACCHI S., VENTURO M., ASIRELLI A., (1999.): I portinnesti del melo, Supplemento L'Informatore Agrario 6: pp. 25-31

SANSAVINI S., LUGLI S., MUSACCHI S., GRANDI M., (2002.): I portinnesti del melo, Supplemento L'Informatore Agrario 51: pp. 17-25

TAGLIAVINI M., SCUDELLARI D., MARANGONI B., BASTIANEL A., FRANZIN F., ZAMBORLINI M., (1992.): Leaf mineral composition of apple tree: sampling date and effect of cultivar and rootstock. J. Plant Nutr. 15 (5): pp. 605-619.

TOMALA K., ANDZIAKL J., KOBUSINSKI K., DZIUBAN Z., (1999.): Influence of rootstocks on fruit maturity and quality of "Jonagold" apples. Apple rootstocks for intensive orchards, pp. 113-114. Warszawa.

YAHA K. AL-HINAI AND TARLYl R., (2004.): Rootstock Effect on Growth and Quality of Gala Apple. HortSience 39 (6): pp. 1231-1233.

Adresa autora - Author's address:

Prof. dr. sc. Ivo Miljković

Čazmanska 2, 10000 Zagreb 
